\title{
Increased coronary sinus lactate concentration during pacing induced angina pectoris after clinical improvement by glyceryl trinitrate
}

\author{
JENS PEDER BAGGER, TORSTEN TOFTEGAARD NIELSEN, PER HENNINGSEN \\ From the Department of Cardiology, Aarhus Kommunehospital, and the Departments of Internal Medicine III and \\ Clinical Chemistry, Aarhus Amtssygehus, Denmark
}

SUMMARY Ten patients with stable angina pectoris and obstructed coronary arteries $(>75 \%$ reduction in diameter) were studied before and during two periods of pacing, the second of which was preceded by sublingual administration of glyceryl trinitrate (mean dose $0.78 \mathrm{mg}$ ). Coronary sinus blood flow measurements and aortocoronary sinus blood sampling for metabolite determinations were carried out. Although the rate of pacing was increased by 10 beats/minute after glyceryl trinitrate administration, the onset of angina was delayed in eight patients during pacing. Drug administration decreased coronary sinus blood flow by $42 \%$ and myocardial oxygen uptake by $41 \%$ during pacing and induced a shift in mean lactate extraction towards a net release (from $3.1 \%$ to $-12 \cdot 6 \%$ ). It increased the number of patients producing lactate from three to five. Glyceryl trinitrate administration decreased myocardial glucose uptake throughout the study, decreased lactate extraction during recovery, and increased the aortocoronary sinus citrate gradient at rest and during recovery, while the exchange of free fatty acids remained unchanged. A decrease in aortocoronary sinus lactate difference during pacing after glyceryl trinitrate administration correlated positively with the fall in coronary sinus blood flow.

The metabolic data do not indicate an augmented myocardial lactate production after glyceryl trinitrate administration. A decrease in coronary sinus blood flow seems, therefore, to be of primary importance in explaining the elevated coronary sinus lactate concentration. Our finding that coronary sinus lactate concentration increased during pacing after glyceryl trinitrate administration despite clinical improvement questions the validity of its use as a quantitative index of ischaemia.

Glyceryl trinitrate is one of the well established agents used in the treatment of angina pectoris. Although the rise in heart rate after administration of the drug enhances myocardial oxygen consumption, this adverse effect is overridden by a peripheral vasodilatation resulting in a decreased myocardial oxygen demand..$^{1-3} \mathrm{~A}$ direct vasodilator effect on the coronary arteries seems to be of minor importance in treating stable angina pectoris. ${ }^{4}$

Previous reports of the influence of glyceryl trinitrate on myocardial metabolism have shown improved lactate extraction after administration of the drug to patients with coronary artery disease. ${ }^{56}$ In these studies atrial pacing was performed at the same frequency before and after its administration. This pro-

Accepted for publication 14 June 1983 cedure does not, however, reproduce the reflex tachycardia which follows peripheral vasodilatation and thus results in a far greater reduction in cardiac work than that after clinical use of glyceryl trinitrate.

Although lactate production results from tissue hypoxia, the production rate does not always reflect myocardial ischaemia quantitatively. ${ }^{7}$ Free fatty acids, the preferred substrate of a well oxygenated heart, restrict myocardial utilisation of carbohydrates. ${ }^{8}$ This restriction might in part be effected at the level of phosphofructokinase owing to citrate accumulation. ${ }^{910}$ Since ischaemia limits the utilisation of free fatty acids, determination of free fatty acid, carbohydrate, and citrate exchanges may be used in addition to lactate determination in assessing ischaemic heart metabolism. ${ }^{11} 12$

The aim of the present study was to evaluate 
myocardial exchanges of free fatty acids, glucose, and citrate during pacing induced angina in patients with chronic coronary artery disease before and after sublingual administration of glyceryl trinitrate. The rate of pacing was increased after administration of the drug in order to imitate the reflex tachycardia which occurs after its clinical use.

\section{Patients and methods}

Ten men (mean age 54 years, range 44-60 years), were studied after informed consent had been obtained. All patients had chronic effort angina with ST segment depression during exercise testing. Six had had a myocardial infarct more than six months previously. All patients were in sinus rhythm and had no evidence of additional heart disease, systemic hypertension, or metabolic disorder. Between two and seven days before the study they underwent left ventriculography and coronary angiography. Stenosis of the coronary arteries resistant to glyceryl trinitrate was considered to be pronounced when the reduction in luminal diameter exceeded $75 \%$. Two patients had pronounced stenosis of three vessels, five of two vessels, and three of one vessel. The left ventricular end diastolic pressure was $15 \pm 7 \mathrm{mmHg}$ and the ejection fraction $56 \pm 19 \%$ (mean $\pm 1 \mathrm{SD}$ ). All medication other than with glyceryl trinitrate was stopped more than one week before the study; glyceryl trinitrate administration was stopped eight hours before the study.

\section{TEST PROCEDURE}

The patients were fasted for 15 hours overnight and examined without sedation in the supine position after resting for 30 minutes. A Wilton-Webster thermodilution catheter was introduced via an antecubital vein into a midposition of the coronary sinus; the position of the catheter was repeatedly checked by fluoroscopy. Changes in heart metabolism have been reported after injection of a contrast medium. ${ }^{13}$ The position of the catheter in the coronary sinus was, therefore, confirmed by oxygen measurements and pressure curves and no contrast medium was given during the study.

A polyethylene catheter was introduced percutaneously through a femoral artery and positioned in the distal aorta. The catheters were kept patent by intermittent flushing with saline containing heparin (total dose 300 units). Coronary sinus blood flow was measured according to the technique of Ganz et al. ${ }^{14}$ by infusing saline ( $36 \mathrm{ml} /$ minute) for 20 to 25 seconds. Coronary sinus pacing was performed at a constant rate (range 130-140 beats/minute) until intolerable angina was induced. Forty minutes after the end of the first pacing period, sublingual glyceryl trinitrate was given in the dose normally taken by the patient (mean dose $0.78 \mathrm{mg}$, range $0.5-1.0 \mathrm{mg}$ ). An interval of at least 45 minutes between the two pacing tests has previously been employed to obtain reproducible metabolic and clinical responses. ${ }^{15}$ Five minutes after the administration of glyceryl trinitrate, a second period of pacing was performed at an increment of 10 beats/minute for each patient. In pilot studies the rate of pacing after administration of the drug was increased to the same level at which the drug increased the heart rate while at rest (about 20 beats/ minute). Nevertheless, because of intolerable angina pacing could not be continued for as long as in the control state. Although the haemodynamic effect of atrial pacing is not the same as that of exercise, myocardial oxygen demand is increased in both. Since the heart rate increases by 10 beats/minute after administration of glyceryl trinitrate during various exercise loads, ${ }^{16}$ we increased the pacing rate by an increment of 10 beats/minute after giving the drug. In each of the 10 patients pacing could then be performed for the same period in the control state and after giving glyceryl trinitrate. To prevent atrioventricular block atropine $0.125 \mathrm{mg}$ was given intravenously before pacing. Care was taken to ensure that the position of the thermodilution catheter was the same during both pacing tests.

Coronary sinus blood flow was determined three times at rest and at three, five, and seven minutes after pacing stopped. During the first pacing period coronary sinus blood flow was determined at about one minute intervals until angina developed. The flow during pacing was calculated as the mean of the last two determinations (in three patients the time before angina developed allowed only one determination). Systolic aortic blood pressure and heart rate were recorded at the same intervals as coronary sinus blood flow.

Blood samples were obtained simultaneously from the coronary sinus and aorta three times at rest and at one, three, five, and seven minutes after pacing stopped. During control pacing one sample was collected after the onset of angina; pacing was, however, continued until the end of sampling. Sampling and haemodynamic measurements were performed at the same time and at the same time intervals before and after drug administration in each patient. During each pacing period a total of $180 \mathrm{ml}$ blood was drawn. This volume was almost compensated for by the saline load given for thermodilution $(170-230 \mathrm{ml})$. Haemoglobin concentration was determined on all samples from the coronary sinus to detect possible dilution by the saline infusion.

Blood samples were analysed for oxygen saturation 11 and immediately collected into heparinised ice cooled glass tubes. Deproteinisation for blood lactate 
Table 1 Haemodynamic data before and after glyceryl trinitrate administration in 10 patients

\begin{tabular}{|c|c|c|c|c|c|}
\hline & \multirow{2}{*}{$\begin{array}{l}\text { Resting } \\
\text { period }\end{array}$} & \multirow[t]{2}{*}{ Pacing } & \multicolumn{3}{|c|}{ Recovery (minutes) } \\
\hline & & & 3 & 5 & 7 \\
\hline $\begin{array}{c}\text { Heart rate } \\
\text { Control } \\
\text { Drug }\end{array}$ & $\begin{array}{l}72 \pm 8 \\
93 \pm 16 \\
p<0.001\end{array}$ & $\begin{array}{l}136 \pm 5 \\
146 \pm 4 \\
p<0.02\end{array}$ & $\begin{array}{l}77 \pm 10 \\
97 \pm 13 \\
p<0.05\end{array}$ & $\begin{array}{l}76 \pm 14 \\
96 \pm 15 \\
p<0.05\end{array}$ & $\begin{array}{l}78 \pm 12 \\
93 \pm 17 \\
p<0.05\end{array}$ \\
\hline $\begin{array}{c}\text { Systolic ao } \\
\text { Control } \\
\text { Drug }\end{array}$ & $\begin{array}{c}131 \pm 11 \\
99 \pm 25 \\
\mathrm{p}<0.005\end{array}$ & $\begin{array}{c}128 \pm 17 \\
98 \pm 21 \\
p<0.005\end{array}$ & $\begin{array}{l}136 \pm 14 \\
103 \pm 22 \\
p<0.001\end{array}$ & $\begin{array}{l}135 \pm 14 \\
104 \pm 22 \\
p<0.001\end{array}$ & $\begin{array}{l}134 \pm 14 \\
104 \pm 20 \\
p<0.001\end{array}$ \\
\hline $\begin{array}{c}\text { Rate-pressu } \\
\text { minute } \\
\text { Control } \\
\text { Drug }\end{array}$ & $\begin{array}{l}93 \pm 12 \\
95 \pm 34 \\
\mathrm{NS}\end{array}$ & $\begin{array}{l}175 \pm 23 \\
143 \pm 32 \\
p<0.02\end{array}$ & $\begin{array}{l}106 \pm 22 \\
100 \pm 29 \\
\text { NS }\end{array}$ & $\begin{array}{l}104 \pm 28 \\
101 \pm 30 \\
\text { NS }\end{array}$ & $\begin{array}{l}105 \pm 27 \\
99 \pm 29 \\
\text { NS }\end{array}$ \\
\hline $\begin{array}{l}\text { Coronary s } \\
\text { Control } \\
\text { Drug }\end{array}$ & $\begin{array}{c}139 \pm 39 \\
91 \pm 24 \\
p<0.005\end{array}$ & $\begin{array}{l}212 \pm 77^{\star} \\
122 \pm 37^{\star} \\
\mathrm{p}<0.005\end{array}$ & $\begin{array}{l}134 \pm 45 \\
100 \pm 37 \\
\text { NS }\end{array}$ & $\begin{array}{l}133 \pm 47 \\
98 \pm 38 \\
\text { NS }\end{array}$ & $\begin{array}{l}132 \pm 57 \dagger \\
99 \pm 34 \dagger \\
\text { NS }\end{array}$ \\
\hline
\end{tabular}

Values are means $\pm S D$. Values at rest are means of three determinations in each patient. $p$ values indicate significance of change between values in control state and after drug administration. NS, not significant.

$\star_{\mathrm{n}}=9 . \dagger_{\mathrm{n}}=8$.

determination and centrifugation for plasma analysis were carried out immediately at $4^{\circ} \mathrm{C}$. After storage at $-20^{\circ} \mathrm{C}$ for a few days, samples were analysed for blood lactate, plasma glucose, plasma free fatty acids, and plasma citrate concentrations as previously described. ${ }^{11}$ The coefficients of variation for duplicate determinations were lactate 0.02 , glucose 0.02 , free fatty acids 0.05 , and citrate 0.02 .

\section{CALCULATIONS AND STATISTICAL ANALYSIS}

Fractional myocardial substrate extraction was calculated as the aortocoronary sinus difference divided by the arterial concentration and multiplied by $100(\%)$. Net substrate flux across the heart was calculated from the aortocoronary sinus difference, haematocrit, and coronary sinus blood flow. The rate-pressure product was determined as the systolic aortic blood pressure multiplied by the heart rate. Data are expressed as mean \pm 1 standard deviation (SD). For statistical analysis we used the correlation coefficient $r$ and Student's $t$ test for paired data. The significance level was 0.05 .

\section{Results}

The mean pacing time of both periods was $276 \mathrm{sec}-$ onds (range 75-600 seconds). All patients developed angina during the first pacing period. After the administration of glyceryl trinitrate two patients experienced no chest pain during repeat pacing. In the remaining eight patients, the onset of angina was significantly delayed by $0(n=2)$ to 90 seconds (mean 33 seconds) $(p<0.02)$.

\section{HAEMODYNAMIC EFFECTS}

After administration of glyceryl trinitrate resting heart rate increased; the systolic blood pressure fell and remained lower throughout the study (Table 1). The change in rate-pressure product was significant only during pacing (decrease of i3\%). Glyceryl trinitrate administration decreased coronary sinus blood flow by $35 \%$ at rest $(p<0.005)$ and by $42 \%$ during pacing $(p<0.005)$; this trend continued during recovery although it was not statistically significant.

Oxygen exchange (Table 2)-Myocardial oxygen consumption fell by $35 \%$ at rest $(p<0.005)$ and by $41 \%$ during pacing $(p<0.005)$ after glyceryl trinitrate administration, which exactly matched the changes in coronary sinus blood flow. The aortocoronary sinus oxygen difference remained unchanged.

METABOLIC EFFECTS (TABLE 2)

Arterial concentration of free fatty acids was stable after glyceryl trinitrate administration; thus the small dose of heparin had no influence on the arterial concentration. A stable haemoglobin concentration in all coronary sinus samples excluded possible dilution by the saline infusion.

Resting state-Glyceryl trinitrate decreased myocardial glucose uptake by $52 \%(p<0.001)$. The mean aortocoronary sinus citrate difference changed from $-5 \pm 3 \mu \mathrm{mol} / 1$ to $-8 \pm 2 \mu \mathrm{mol} / 1 \quad(\mathrm{p}<0.05)$, whereas myocardial citrate release was constant.

Pacing-After glyceryl trinitrate administration mean myocardial lactate extraction became negative (from $3 \cdot 1 \pm 30 \cdot 2 \%$ to $-12 \cdot 6 \pm 30 \cdot 6 \% ; \mathrm{p}<0 \cdot 001$ ). Mean uptake of lactate $(2.8 \pm 53.0 \mu \mathrm{mol} / \mathrm{minute})$ changed to 
Table 2 Myocardial exchange of substances before and after glyceryl trinitrate administration in 10 patients undergoing atrial pacing

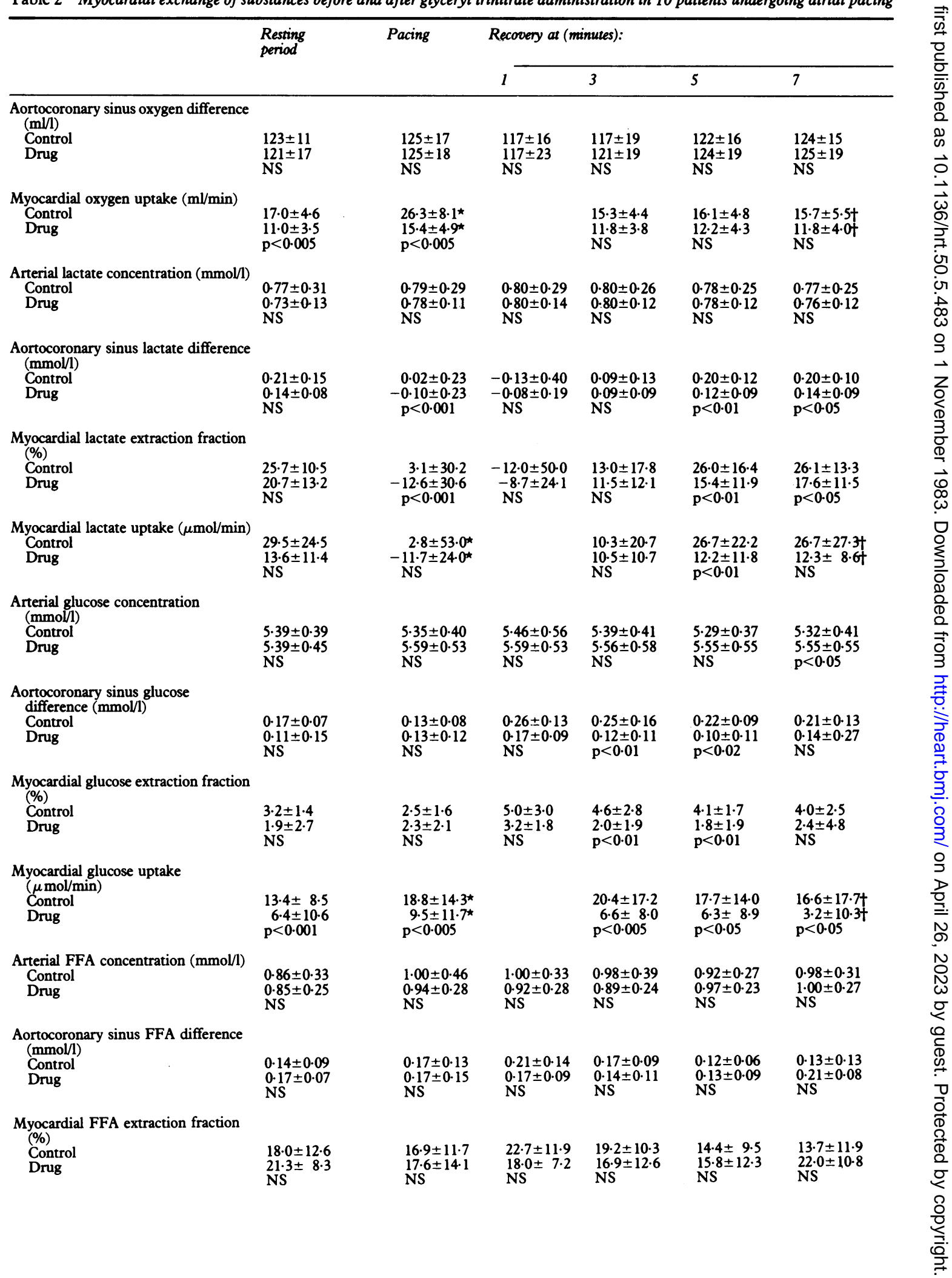


Table 2 (cont)

\begin{tabular}{|c|c|c|c|c|c|c|}
\hline & \multirow{2}{*}{$\begin{array}{l}\text { Resting } \\
\text { period }\end{array}$} & \multirow[t]{2}{*}{ Pacing } & \multicolumn{4}{|c|}{ Recooery at (minutes): } \\
\hline & & & 1 & 3 & 5 & 7 \\
\hline $\begin{array}{l}\text { Myocardial FFA uptake }(\mu \mathrm{mol} / \mathrm{min}) \\
\text { Control } \\
\text { Drug }\end{array}$ & $\begin{array}{l}10 \cdot 7 \pm 7 \cdot 3 \\
8 \cdot 8 \pm 4 \cdot 9 \\
\text { NS }\end{array}$ & $\begin{array}{l}18 \cdot 8 \pm 11 \cdot 8^{\star} \\
9 \cdot 5 \pm 9 \cdot 8^{\star} \\
\text { NS }\end{array}$ & • & $\begin{array}{l}12 \cdot 6 \pm 8 \cdot 5 \\
7 \cdot 8 \pm 5 \cdot 8 \\
\text { NS }\end{array}$ & $\begin{array}{l}8 \cdot 5 \pm 6 \cdot 2 \\
7 \cdot 9 \pm 7 \cdot 2 \\
\text { NS }\end{array}$ & $\begin{array}{l}8.6 \pm 8 \cdot 0+ \\
10 \cdot 6 \pm 6 \cdot 9+ \\
\text { NS }\end{array}$ \\
\hline $\begin{array}{l}\text { Arterial citrate concentration }(\mu \mathrm{mol} / \mathrm{l}) \\
\text { Control } \\
\text { Drug }\end{array}$ & $\begin{array}{l}78 \pm 15 \\
81 \pm 13 \\
\mathrm{NS}\end{array}$ & $\begin{array}{l}77 \pm 14 \\
82 \pm 13 \\
p<0.05\end{array}$ & $\begin{array}{l}79 \pm 15 \\
85 \pm 14 \\
p<0.05\end{array}$ & $\begin{array}{l}79 \pm 15 \\
84 \pm 13 \\
p<0.05\end{array}$ & $\begin{array}{l}80 \pm 15 \\
84 \pm 14 \\
\text { NS }\end{array}$ & $\begin{array}{l}80 \pm 14 \\
84 \pm 13 \\
\mathrm{NS}\end{array}$ \\
\hline $\begin{array}{l}\text { Aortocoronary sinus citrate difference } \\
(\mu \mathrm{mol} / \mathrm{l}) \\
\text { Control } \\
\text { Drug }\end{array}$ & $\begin{array}{l}-5 \pm 3 \\
-8 \pm 2 \\
p<0.05\end{array}$ & $\begin{array}{l}-4 \pm 4 \\
-6 \pm 3 \\
\text { NS }\end{array}$ & $\begin{array}{l}-6 \pm 3 \\
-8 \pm 4 \\
\text { NS }\end{array}$ & $\begin{array}{l}-8 \pm 3 \\
-11 \pm 4 \\
\text { NS }\end{array}$ & $\begin{array}{l}-6 \pm 4 \\
-12 \pm 3 \\
p<0.001\end{array}$ & $\begin{array}{l}-5 \pm 5 \\
-9 \pm 3 \\
p<0.02\end{array}$ \\
\hline $\begin{array}{l}\text { Myocardial citrate release }(\mu \mathrm{mol} / \mathrm{min}) \\
\text { Control } \\
\text { Drug }\end{array}$ & $\begin{array}{l}0 \cdot 4 \pm 0 \cdot 3 \\
0 \cdot 3 \pm 0 \cdot 2 \\
\text { NS }\end{array}$ & $\begin{array}{l}0.3 \pm 0.6^{\star} \\
0.4 \pm 0 \cdot 2^{\star} \\
\mathrm{NS}\end{array}$ & & $\begin{array}{l}0.6 \pm 0.3 \\
0.6 \pm 0.3 \\
\text { NS }\end{array}$ & $\begin{array}{l}0.5 \pm 0.4 \\
0.6 \pm 0.5 \\
\text { NS }\end{array}$ & $\begin{array}{l}0.5 \pm 0.2+ \\
0.5 \pm 0.3+ \\
\mathrm{NS}\end{array}$ \\
\hline
\end{tabular}

Values are means $\pm S D$. Values at rest are means of three determinations in each patient. $p$ values indicate significance of change between values in control state and after drug administration. NS, not significant; FFA, free fatty acids.

$\star_{n}=9 . t_{n}=8$.

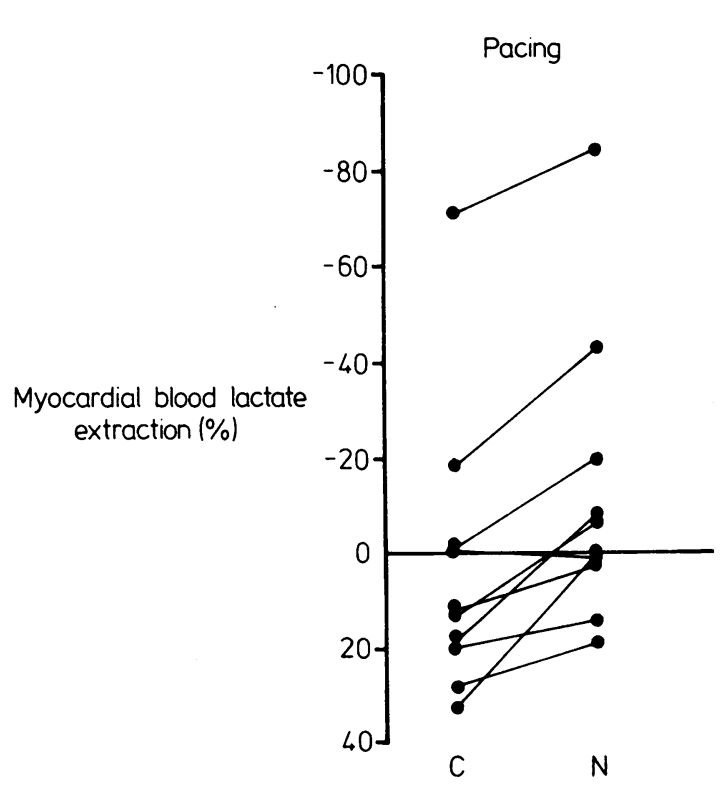

Fig. 1 Myocardial lactate extraction fraction during pacing before $(C)$ and after administration of glyceryl trinitrate $(N)$ $(n=10)$.
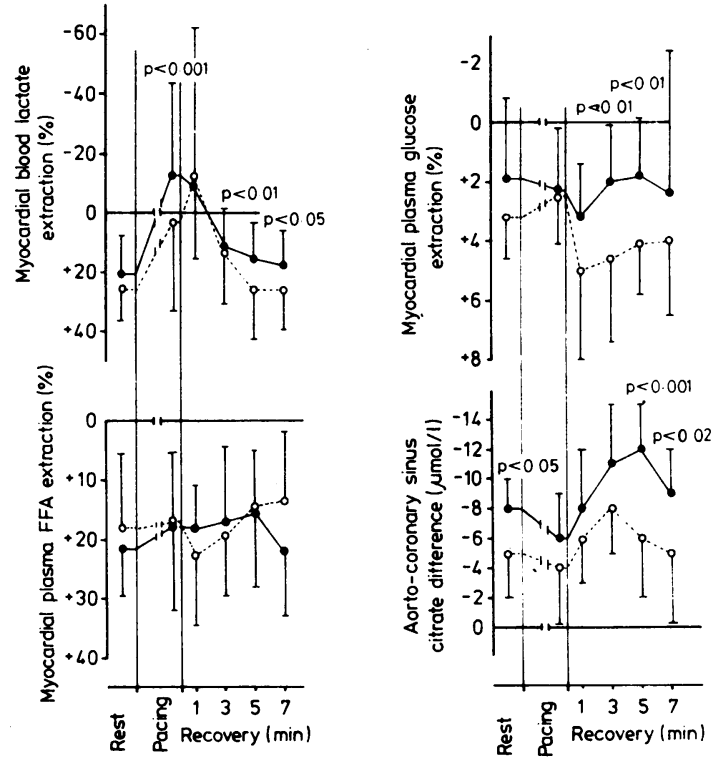

Fig. 2 Myocardial extraction fractions of blood lactate, plasma glucose, and plasma free fatty acids (FFA) and aortocoronary sinus citrate difference before, during, and after pacing in control state $(O)$ and after glyceryl trinitrate administration $(O)(n=10)$. Bars represent means $\pm S D$. 


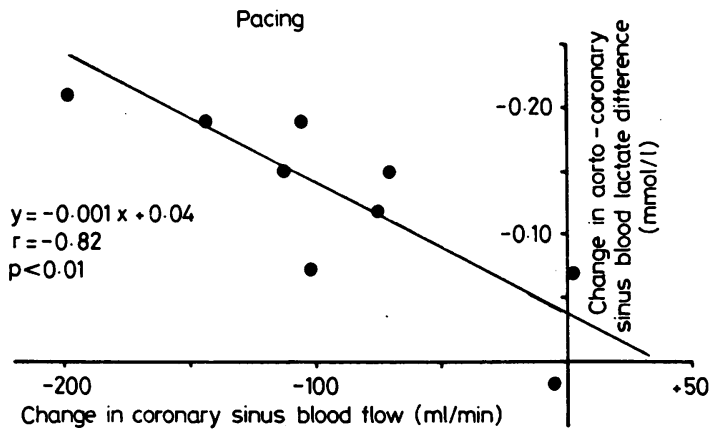

Fig. 3 Relation between changes in aortocoronary sinus lactate difference and in coronary sinus blood flow before and after glyceryl trinitrate administration during pacing $(n=9)$.

a net lactate release of $11.7 \pm 24.0 \mu \mathrm{mol} /$ minute; this was not, however, statistically significant. Thus administration of glyceryl trinitrate decreased myocardial lactate extraction and in two patients produced a change from lactate extraction to lactate release (Fig. 1). The decrease in mean aortocoronary sinus lactate difference correlated positively with the fall in coronary sinus blood flow $(p<0.01)$ (Fig. 3). After drug administration myocardial uptake of glucose and free fatty acids decreased by $50 \%$, which was significant only for glucose. Mean aortocoronary sinus citrate difference and myocardial citrate release did not change significantly after drug administration.

Recovery-Glyceryl trinitrate administration decreased myocardial lactate extraction significantly at five and seven minutes (Fig. 2) and lactate uptake at five minutes. Glucose uptake was significantly reduced by a factor of 3 to 5 throughout recovery and glucose extraction was significantly halved at three and five minutes after giving the drug (Fig. 2). The mean aortocoronary sinus citrate difference became increasingly negative from $-6 \pm 4 \mu \mathrm{mol} / \mathrm{l}$ to $-12 \pm 3 \mu \mathrm{mol} / \mathrm{l}$ at five minutes $(\mathrm{p}<0.001)$ and from $-5 \pm 5 \mu \mathrm{mol} / 1$ to $-9 \pm 3 \mu \mathrm{mol} / 1(p<0.02)$ at seven minutes after glyceryl trinitrate administration (Fig. 2). Myocardial citrate release remained unchanged. Exchanges of free fatty acids were the same after glyceryl trinitrate administration.

\section{Discussion}

In the present study glyceryl trinitrate relieved pacing induced angina in eight out of 10 patients with coronary artery disease despite the fact that the pacing rate was increased after drug administration.

The antianginal effect of glyceryl trinitrate is mainly related to its peripheral vasodilator properties. ${ }^{2} 4$ Venous return, blood pressure, and afterload are reduced. ${ }^{2}$ This results in a reduction in heart size and intraventricular pressure with a subsequent decrease in wall tension, a major determinant of myocardial oxygen requirements. ${ }^{13}$ As a result of the decreased blood pressure a reflex tachycardia develops. ${ }^{317}$ An increase in heart rate of 10 beats/ minute has been reported after glyceryl trinitrate administration during varying exercise loads. ${ }^{16} \mathrm{We}$ increased the pacing rate by the same amount after glyceryl trinitrate administration to maintain tachycardia during pacing and to avoid too great a reduction in cardiac work. Although a rise in heart rate increases myocardial oxygen consumption, our study produced a decrease in myocardial oxygen uptake during pacing. This result indicates that cardiac work was reduced after administration of glyceryl trinitrate in accordance with the clinical improvement in the patient's condition.

The rate-pressure product has been used as a clinical predictor of myocardial oxygen demand.18 Our finding that this product remained unchanged at rest after glyceryl trinitrate administration (Table 1) despite reduced oxygen uptake (Table 2) indicates that the rate-pressure product should not be used when estimating myocardial oxygen consumption after administration of the drug. ${ }^{17}$

The fall in coronary sinus blood flow at rest and during pacing in this study is consistent with that in other reports ${ }^{419}$ and probably reflects the decreased cardiac work after glyceryl trinitrate administration. Although glyceryl trinitrate thus lowered cardiac work and delayed the onset of angina during pacing, a higher coronary sinus lactate concentration was found in all except one patient, which resulted in a significantly decreased lactate extraction for the total group (Figs. 1 and 2).

Increased coronary sinus lactate concentration may be caused by either an increased myocardial lactate production or a decrease in coronary sinus blood flow. As the decrease in aortocoronary sinus lactate difference correlated positively with the fall in coronary sinus blood flow during pacing (Fig. 3), the changes in coronary sinus blood flow seem to have been of primary importance in our study.

The finding that in two patients lactate uptake changed to lactate release (Fig. 1), and the tendency for a mean increase in lactate output during pacing after glyceryl trinitrate administration (Table 2), may reflect regional haemodynamic effects of the drug. Administration of the drug increases the relative flow in the endocardium and in hypoperfused regions. ${ }^{19-21}$ Thus a glyceryl trinitrate mediated redistribution of blood flow with faster regional lactate washout might further increase coronary sinus lactate concentration, lactate production remaining unchanged (Fig. 2).

Our data argue against the possibility that the 
increased coronary sinus lactate concentration after glyceryl trinitrate administration was due to increased lactate production. Mean glucose and free fatty acid uptake tended to decrease equally during pacing (by about $50 \%$ ) (Table 2). The fall in the uptake of both substrates corresponded closely with the reduction in coronary sinus blood flow as fractional extractions remained constant (Table 2). Our results on myocardial citrate exchange further support this view. Owing to the inhibition of the glycolytic key enzyme phosphofructokinase myocardial citrate concentration is considered to be a main regulatory monitor of the glycolytic pathway..$^{8-10} \mathrm{We}$ have previously reported an inverse relation between the transmyocardial plasma citrate gradient and carbohydrate utilisation and have suggested that the aortocoronary sinus plasma citrate difference is a marker of glycolytic activity. ${ }^{11}$ In the present study the aortocoronary sinus plasma citrate difference did not change during pacing (Fig. 2).

In fact, our metabolic data at rest and during recovery suggest a relatively decreased carbohydrate utilisation and unchanged free fatty acid uptake after glyceryl trinitrate administration. The glucose uptake decreased throughout the study and fractional extractions of both glucose and lactate decreased during recovery. By contrast, free fatty acid extraction remained unchanged and no convincing tendency of a reduced uptake of free fatty acids was found at rest or during recovery. In support of an inhibited glucose utilisation, significantly more negative aortocoronary sinus plasma citrate differences were found at rest and during recovery (Fig. 2).

Lactate release across the heart is considered to be of great diagnostic value in establishing the presence of ischaemia in patients with coronary artery disease. ${ }^{22-24}$ From tracer studies ${ }^{25}$ and measurements of net chemical lactate exchanges 1224 a relation has been found between the magnitude of lactate release and the degree of coronary artery stenosis. A change in myocardial lactate metabolism towards increased extraction has been widely used as evidence that a treatment improves myocardial function. 1522 Nevertheless, case reports of an unaccountable increase in myocardial lactate production after intervention have been published. ${ }^{26}$ Our finding of an increased coronary sinus lactate concentration during pacing after glyceryl trinitrate administration despite clinical improvement questions the validity of lactate determinations as a quantitative index of ischaemia, particularly after drugs or treatment that change coronary sinus blood flow have been used.

This work has been supported by grants from the Danish Heart Association.

\section{References}

1 Sonnenblick EH, Ross J Jr, Braunwald E. Oxygen consumption of the heart. Am $\mathcal{f}$ Cardiol 1968; 22: 328-36.

2 Mason DT, Braunwald E. The effects of nitroglycerin and amyl nitrite on arteriolar and venous tone in the human forearm. Circulation 1965; 32: 755-66.

3 Lee SJK, Sung YK, Zaragoza AJ. Effects of nitroglycerin on left ventricular volumes and wall tension in patients with ischaemic heart disease. Br Heart $\mathcal{f}$ 1970; 32: $790-4$.

4 Ganz W, Marcus HS. Failure of intracoronary nitroglycerin to alleviate pacing-induced angina. Circulation 1972; 46: 880-9.

5 Chiong MA, West RO, Parker JO. Influence of nitroglycerin on myocardial metabolism and hemodynamics during angina induced by atrial pacing. Circulation 1972; 45: $1044-56$.

6 Kugler G. Myocardial release of inosine, hypoxanthine and lactate during pacing-induced angina in humans with coronary artery disease. Eur $\mathcal{F}$ Cardiol 1979; 9: 227-40.

7 Apstein CS, Gravino F, Hood WB Jr. Limitations of lactate production as an index of myocardial ischemia. Circulation 1979; 60: 877-88.

8 Neely JR, Morgan HE. Relationship between carbohydrate and lipid metabolism and the energy balance of heart muscle. Annu Rev Physiol 1974; 36: 413-59.

9 Parmeggiani A, Bowman RH. Regulation of phosphofructokinase activity by citrate in normal and diabetic muscle. Biochem Biophys Res Commun 1963; 12: 268-73.

10 Garland PB, Randle PJ, Newsholme EA. Citrate as an intermediary in the inhibition of phosphofructokinase in rat heart muscle by fatty acids, ketone bodies, pyruvate, diabetes and starvation. Nature 1963; 200: 169-70.

11 Nielsen TT, Henningsen P, Bagger JP, Thomsen PEB, Eyjolfsson K. Myocardial citrate metabolism in control subjects and patients with coronary artery disease. Scand f Clin Lab Invest 1980; 40: 575-80.

12 Bagger JP, Nielsen TT, Henningsen P, Thomsen PEB, Eyjolfsson K. Myocardial release of citrate and lactate during atrial pacing-induced angina pectoris. Scand $\mathcal{F}$ Clin Lab Invest 1981; 41: 431-9.

13 Wisneski JA, Gertz EW, Neese R, et al. Myocardial metabolic alterations after contrast angiography. $A m \mathcal{F}$ Cardiol 1982; 50: 239-45.

14 Ganz W, Tamura K, Marcus HS, Donoso R, Yoshida S, Swan HJC. Measurement of coronary sinus blood flow by continuous thermodilution in man. Circulation 1971; 44: 181-95.

15 Jackson G, Atkinson L, Oram S. Improvement of myocardial metabolism in coronary arterial disease by beta-blockade. Br Heart F 1977; 39: 829-33.

16 Goldstein RE, Rosing DR, Redwood DR, Beiser GD, Epstein SE. Clinical and circulatory effects of isosorbide dinitrate. Comparison with nitroglycerin. Circulation 1971; 43: 629-40.

17 Goldstein RE, Epstein SE. Medical management of patients with angina pectoris. Prog Cardiovasc Dis 1972; 14: 360-98.

18 Holmberg S, Serzysko W, Varnauskas E. Coronary circulation during heavy exercise in control subjects and patients with coronary heart disease. Acta Med Scand 1971; 190: 465-80. 
19 Engel H-J, Wolf R, Hundeshagen H, Lichtlen PR. Different effects of nitroglycerin and nifedipine on regional myocardial blood flow during pacing induced angina pectoris. Eur Heart f 1980; 1 (suppl B): 53-8.

20 Brown BG, Bolson E, Petersen RB, Pierce CD, Dodge HT. The mechanisms of nitroglycerin action: stenosis vasodilatation as a major component of the drug response. Circulation 1981; 64: 1089-97.

21 Goldstein RE, Stịnson EB, Scherer JL, Seningen RP, Grehl TM, Epstein SE. Intraoperative coronary collateral function in patients with coronary occlusive disease. Circulation 1974; 49: 298-308.

22 Chatterjee K, Matloff JM, Swan HJC, et al. Abnormal regional metabolism and mechanical function in patients with ischemic heart disease. Circulation 1975; 52: 390-9.

23 Herman MV, Elliott WC, Gorlin R. An electrocardiographic, anatomic, and metabolic study of zonal myocardial ischemia in coronary heart disease. Circulation 1967; 35: 834-46.
24 Jackson G, Atkinson L, Clark M, Crook B, Armstrong $P$, Oram S. Diagnosis of coronary artery disease by estimation of coronary sinus lactate. Br Heart $\mathcal{F}$ 1978; 40: 979-83.

25 Gertz EW, Wisneski JA, Neese R, Bristow JD, Searle GL, Hanlon JT. Myocardial lactate metabolism: evidence of lactate release during net chemical extraction in man. Circulation 1981; 63: 1273-9.

26 Chatterjee K, Rouleau JL, Parmley WW. Haemodynamic and myocardial metabolic effects of captopril in chronic heart failure. Br Heart $\mathcal{F}$ 1982; 47: 2338.

Requests for reprints to Dr J P Bagger, Department of Cardiology, Aarhus Kommunehospital, 8000 Aarhus C, Denmark. 